\title{
TRADUÇÃO: CONSIDERAÇÕES HISTÓRICAS E DEFINIÇÕES
}

\author{
Joice Maria Maltauro Juliano - Especialista. Professora de Língua Inglesa da UTFPR - \\ Unidade de Medianeira. joice@md.cefetpr.br
}

\section{Simone Francescon Cittolin - Especialista. Professora de Língua Inglesa da UTFPR- Unidade de Medianeira e professora de Língua Inglesa da UNIPAR - Universidade Paranaense.sfcittolin@md.cefetpr.br}

\section{Resumo}

\begin{abstract}
A tradução é uma das estratégias de ensino para a aquisição de uma língua estrangeira que muito tem sido discutida nos últimos tempos, no que se refere aos mecanismos utilizados para que a língua seja aprendida com sucesso. Para se fazer uma reflexão a respeito da tradução enquanto um dos mecanismos de ensino de línguas, é imprescindível que se tenha clareza de como é definida por alguns autores. Será feita, primeiramente, um breve comentário sobre a história da tradução e então uma exposição de definições sobre a mesma na opinião de alguns estudiosos.
\end{abstract}

Palavras-chave: Tradução, estratégia, aprendizagem, aquisição, língua

Apesar de a tradução não ter a aprovação da maioria dos professores de língua estrangeira, há quem considere que ela também possa ter sua parcela de contribuição na aquisição eficiente de uma língua estrangeira ou segunda língua.

A tradução, então, como uma ferramenta de ensino, apesar de eliminada do discurso de muitos professores, sempre esteve presente nas aulas de língua estrangeira, lado a lado com a cópia, a repetição, a leitura em voz alta e com trabalhos em pares, o que confirma que ela ainda continua sendo bastante usada. Nós professores de língua estrangeira, sabemos que mesmo que façamos a tradução oral ou mímicas de apenas aquelas palavras que percebemos que o aluno não conseguiu entender através de nossa explicação na língua alvo, nossos alunos fazem o que estudiosos chamam de tradução mental, que é uma ocorrência involuntária por parte do aluno, ou seja, é automática.

Através deste estudo não se quer afirmar que em nossas aulas de língua estrangeira devemos adotar a tradução como método de ensino devido a essa ação involuntária do aluno, mas mostrar o que é a tradução segundo alguns autores para, em estudos posteriores, verificar se as atividades de tradução podem contribuir ou não para a aquisição e o aprendizado de uma língua. Portanto considera-se interessante estudar um pouco a respeito da história da tradução e o que é a tradução segundo alguns autores. 


\section{CONSIDERAÇÕES HISTÓRICAS SOBRE A TRADUÇÃO}

Friedrich (1992) afirma que a história da teoria da tradução começa com o Império Romano, quando a tradução significava incorporar o assunto da cultura estrangeira em uma cultura própria de uma língua sem prestar atenção às características lexicais ou estilísticas dos textos originais da língua-fonte (origem).

Se no Império Romano a apropriação de conteúdo parecia despertar maior interesse nos tradutores, durante o período da Renascença, estes exploravam como as estruturas lingüísticas de uma ou de outra língua poderiam enriquecer a sua própria. Dessa forma, nesses dois períodos, a tradução era vista como uma exploração rigorosa da original para acentuar as dimensões estéticas e lingüísticas de sua própria língua. Então, tradutores e escritores, através de mudanças, no século XVIII, começaram a ver outras línguas como iguais e não como formas inferiores de expressão, em comparação com suas próprias línguas.

Segundo alguns estudiosos, a profissão de tradutor e intérprete é bastante antiga na América. Chegou com Cristóvão Colombo, há 500 anos, e surgiu da necessidade de comunicação com os nativos das terras recém descobertas.

Como só havia intérpretes dos idiomas árabe e hebreu, Colombo trouxe alguns nativos para serem guias e futuros intérpretes. Assim, descobridores e conquistadores tiveram facilitada sua tarefa com o auxílio desses intérpretes, que eram chamados "línguas". Esses línguas podiam atuar como intérpretes nos julgamentos, junto aos nativos e até nas "audiências reais". Para exercer esta função, tinham que jurar que usariam sua profissão para o bem e com lealdade.

Apesar de não estarmos tratando, especificamente, da tradução feita por tradutores, e, sim, da tradução no ensino de línguas estrangeiras, no Brasil, o tradutor deve conhecer, em profundidade, a teoria da tradução que, através de seus aspectos técnicos, Ihe permitirá um melhor desempenho na prática da tradução de textos variados, pertençam eles ao campo humanístico, científico ou técnico.

\section{DEFINIÇÕES SOBRE A TRADUÇÃO}

Para realizar uma reflexão a respeito do uso da tradução/língua materna nas aulas de língua estrangeira, é relevante que conheçamos algumas definições atribuídas à tradução, pois esta, por sua vez parece receber diferentes interpretações, dependendo da situação em que acontece.

Campos (1986, p. 07), diz que, segundo os dicionários, "tradução é o 'ato ou efeito de traduzir'” e "traduzir vem do verbo latino traducere, que significa 'conduzir ou fazer passar de um lado para outro'" e define, então, que "traduzir nada mais é que isto: fazer passar de uma língua para outra, um texto escrito na primeira delas. Quando o texto é oral, falado, diz-se que há 'interpretação', e quem a realiza então é um intérprete". Portanto percebe-se que na visão do autor, a tradução 
falada não seria uma tradução e sim uma interpretação.

O autor destaca, ainda, que a tradução, enquanto passagem de um texto de uma língua para outra, certas vezes está relacionada ao léxico, ás vezes a sintaxe, outras vezes, à morfologia da língua que se está traduzindo e da língua para a qual se está traduzindo.

Cabe ressaltar, ainda, que este autor defende que nenhuma tradução pode ter a pretensão de substituir o texto original, pois é apenas uma tentativa de recriação dele. E sempre poderão ser feitas outras tentativas.

Não se traduz afinal de uma língua para outra, e sim de uma cultura para outra; a tradução requer assim, do tradutor qualificado, um repositório de conhecimentos gerais, de cultura geral, que cada profissional irá aos poucos ampliando e aperfeiçoando de acordo com os interesses do setor a que se destine o seu trabalho. (CAMPOS, 1986, p.27,28).

A tradução se orienta através de dois fatores que são chamados de equivalência textual e correspondência formal. Isto quer dizer que "uma boa tradução deve atender tanto ao conteúdo quanto à forma do original, pois a equivalência textual é uma questão de conteúdo, e a correspondência formal, como o nome está dizendo, é uma questão de forma" (p.49).

A tradução entre línguas diferentes como um processo de comunicação, inevitavelmente, tem alguma perda de informação como qualquer situação de comunicação e pode ser considerada como um fator implícito nesse processo.

Para Frota (1999, p.55), (...) a tradução passa a ser considerada uma reescritura, um texto que inevitavelmente transforma 0 texto estrangeiro, não só devido às diferenças estritamente lingüísticas, mas, sobretudo, devido as diferentes funções que o texto traduzido pode ter na cultura de chegada.

Portanto, a tradução, segundo a autora desse ensaio, passa por uma situação de reescrita, devido às diferenças lingüísticas, mas, principalmente, devido às diferenças culturais da outra língua.

Já, Wyler (1999, p.97), parte do pressuposto de que a tradução é uma interação verbal, cuja forma e tema se encontram ligados às condições sociais e reagem de forma muito sensível às flutuações dessas condições.

Na visão de Ladmiral (1979, p.15),

A tradução é um caso particular de convergência lingüística: no sentido mais amplo, ela designa qualquer forma de 'mediação interlingüística' que permita transmitir informação entre locutores de línguas diferentes. A tradução faz passar uma mensagem de uma língua de partida (LP), ou língua-fonte, para uma língua de chegada (LC), ou línguaalvo.

Widdowson (1997) considera que a tradução naturalmente nos leva a associar a língua a ser aprendida com a que já conhecemos e usá-la para explorar e aumentar o conhecimento. Ela proporciona a apresentação da língua estrangeira como uma atividade relevante e significativa 
comparada à língua materna do aprendiz. Permite, também, a invenção de exercícios que envolvem a resolução de problemas de comunicação que exigem conhecimento além do simplesmente lingüístico.

Este princípio naturalmente nos leva a associar a língua a ser aprendida ao que ele já sabe e a usar a língua para a exploração e extensão do seu conhecimento. Para usar a língua, em resumo, da forma que ela é, normalmente usada. (...) Ela propicia a apresentação da língua estrangeira como uma atividade comunicativa relevante e significativa comparada a apropria língua do aprendiz. Ela permite a invenção de exercícios que envolvem a solução de problemas comunicativos, problemas que exigem referência além da simplesmente lingüística, que demanda habilidades lingüísticas somente a tal ponto que eles sejam uma característica de habilidades comunicativas. (Widdowson, 1997, p.158,159)

Muitos escritores como Humboldt (1992, p. 03,04), destacam que: "Nem toda palavra de uma língua tem um equivalente exato na outra. Dessa forma, nem todos o conceitos que são expressados através de palavras de uma língua, são exatamente os mesmos que são expressados através de palavras de uma outra". O que significa que não existe uma palavra equivalente a cada uma das outras na língua estrangeira, portanto, nem todas as palavras que expressam um conceito em uma língua o farão em outra. Será preciso entender o significado e então transpor para a língua a ser traduzida com a estrutura e as palavras que forem necessárias e que não serão, necessariamente, as do texto original.

Paz (1992, p.07) afirma que também estamos diante de um tipo de tradução, quando ela acontece entre línguas e dentro de uma mesma língua. O que não é diferente da tradução entre duas línguas, quando o aluno não entende uma determinada palavra na sua língua materna e pede explicação.

Schulte E Biguenet (1992, p. 09) dizem, de forma resumida, que ler também é traduzir e que o processo de tradução se constitui pelo entendimento humano secreto do mundo e da comunicação social. A língua, por si só, é uma tradução e o ato de recriá-la, através do processo de leitura, constitui uma outra tradução. Dessa forma, a tradução funciona como uma forma de revitalização da língua, que pode estimular a criação de novas palavras na língua traduzida e influenciar as estruturas gramaticais e semânticas da mesma, portanto, pode ser vista como enriquecimento da língua.

Dryden (1961, p. 17) destaca que toda tradução pode ser reduzida a três partes: a metafrase, a paráfrase e a imitação. A metafrase é a tradução feita palavra por palavra; a paráfrase acontece quando o tradutor se mantém na visão do autor, mas focalizado no sentido e não na tradução termo por termo e a imitação, na qual o tradutor, se é que ainda pode ser considerado assim, assume a liberdade de não somente variar as palavras e o sentido, mas também de abandonálos e pegar só idéias gerais do original e fazer a tradução como quer. Mas esse autor afirma, também, que o tradutor tem que compreender perfeita e inteiramente o sentido do autor, a natureza de seu assunto e os termos ou assunto tratado e então traduzir, ao invés de traduzir palavra por palavra, o que é bastante tedioso, confuso, além de correr-se o risco até mesmo de distorcer o sentido do texto, se não for interpretado corretamente. 
Para Schopenhauer (1992), nem toda palavra tem uma equivalente exata em outra língua. Portanto, nem todas as palavras que expressam um conceito em uma língua o fazem da mesma maneira na outra. Para certos conceitos, a palavra existe só em uma língua e, então, é adotada por outras línguas.

Então, quando se aprende uma língua, nosso problema principal está em entender cada conceito para o qual a língua estrangeira tem uma palavra, mas que na nossa própria língua falta um equivalente exato, portanto não se pode aprender somente palavras e sim adquirir conceitos. Nós nunca entenderemos o sentido do que é falado na língua estrangeira, se primeiro traduzirmos palavra por palavra na nossa língua materna.

O autor destaca, ainda, que pessoas limitadas intelectualmente não dominarão, facilmente, uma língua estrangeira, pois, na verdade, aprendem as palavras e tentam aproximar tudo o que aprendem da língua materna, portanto são incapazes de adquirir o 'espírito' da língua estrangeira.

"De tudo isso, se torna claro que novos conceitos são criados durante o processo de aprendizagem da língua estrangeira para dar significados a novos signos" (SCHOPENHAUER, 1992, p.34). E que um número infinito de nuances, similaridades e relações entre objetos aumentam o nível de consciência de uma nova língua, o que confirma que nosso pensamento é modificado e inovado através da aprendizagem de cada língua estrangeira, e que o poliglotismo representa, além de suas vantagens imediatas, um meio direto de educar a mente pela correção e perfeição de nossas percepções, através da diversidade e refinamento dos conceitos.

Schopenhauer (1992) defende que a tradução é um assunto de necessidade para a nação da qual somente uma pequena parte pode adquirir conhecimento suficiente de línguas estrangeiras.

Uma tradução não pode e não deveria ser um comentário. Não deveria ser ambígua, devido ao pouco entendimento, a não ser quando o original não expressa claramente suas idéias. A tradução é um meio e, para ser compreendida como tal, deve se voltar ao original.

Schleiermacher (1992, p.108) diz que a tradução pode ser feita tanto na direção do autor quanto na do leitor. Ou o autor é trazido para a linguagem do leitor, ou o leitor é levado para a linguagem do autor. No primeiro caso, não se faz uma tradução, e sim, uma imitação ou uma paráfrase do texto original.

Jakobson (1992) afirma que temos três diferentes maneiras de interpretar o signo verbal. Ele pode ser traduzido em outros signos da mesma língua, em outra língua, ou em outro sistema de símbolos não verbal. Esses três tipos de tradução podem ser: a tradução intralingual, que é uma interpretação de signos verbais por meio de outros signos da mesma língua; a tradução interlingual, que é a interpretação de signos verbais por meio de alguma outra língua e a tradução intersemiótica, que é uma interpretação de signos verbais por meio de um sistema de signos não verbais. 
A tradução intralingual de uma palavra, dentro de uma mesma língua, usa tanto uma outra palavra como outros recursos mais ou menos sinônimos, para uma circunlocução. Uma palavra ou expressão idiomática só pode ser completamente interpretada por meio de uma combinação equivalente de unidades de códigos. Já, no nível da tradução interlingual, não há equivalência completa entre códigos, as mensagens podem servir como interpretações adequadas de códigos ou mensagens estrangeiras.

Mais freqüentemente, entretanto, a tradução de uma língua, dentro de uma outra, substitui mensagens em uma língua, não por unidades de códigos separados, mas por mensagens inteiras em algumas outras línguas. Tal tradução é um discurso direto, ou seja, o tradutor recodifica e transmite a mensagem recebida de uma outra fonte. Então, a tradução envolve duas mensagens equivalentes em dois códigos diferentes, em duas línguas diferentes.

Para Paz (1992, p.152), quando aprendemos a falar, estamos aprendendo a traduzir. A criança, que pede a sua mãe para dizer o significado de uma palavra, está pedindo para que a traduza para um termo familiar, já conhecido dela. Nesse caso, a tradução dentro de uma língua não é diferente da tradução entre duas línguas. Para esse autor, a tradução, palavra por palavra, não é impossível, ele apenas não a considera tradução, mas um mecanismo que ajuda no entendimento do texto em sua língua original. O autor afirma, ainda, que, mesmo quando a intenção da tradução é significação, no caso de textos científicos, ela implica na transformação do texto original.

Há uma ligação inegável e muito importante entre a semântica e a tradução, de acordo com Schogt (1992), pois uma lida com o significado e a outra, com a transferência do significado. Mas as teorias da semântica e da tradução não estão conectadas proximamente e, freqüentemente, especialistas de tradução sentem-se incomodados ao invés de ajudados pelos princípios da teoria da semântica.

Dizer que a semântica se preocupa com o significado é simples, no entanto, é necessário que se esclareça as principais questões que ela investiga, as quais, segundo o autor, seguem uma ordem de importância. Em primeiro lugar, a semântica estuda os problemas filosóficos e epistemológicos da relação entre as línguas, pensamento (reflexão) e mundo externo; em segundo, a relação entre o elemento significativo de uma língua e os outros elementos do mesmo nível de análise, que se encontram nessa língua e, em terceiro, a comunicação entre indivíduos que falam a mesma língua, seja oral ou escrita.

No primeiro caso, pode-se dizer, de maneira geral, sem se referir a uma língua específica, que há uma relação grande entre língua, pensamento e realidade, pois realidades diferentes geram línguas diferentes e vice-versa. Até mesmo as pessoas, que pensam ter aprendido uma língua estrangeira, continuam presas aos sistemas da língua-mãe, e são, então, incapazes de se comunicar efetivamente na língua que pensam dominar.

A segunda questão trata dos elementos da estrutura lingüística e descreve-os do ponto de vista funcional, ao invés de se referir a qualquer característica física, que pode estar isolada. Tal 
fenômeno é mais conhecido como fonologia/fonemas. Dessa forma, os esforços feitos até agora para estruturar unidades significativas, tal como é feito com os fonemas, têm alcançado, apenas, sucesso parcial.

De acordo com a terceira idéia, a comunicação acontece quando alguém formula uma mensagem e alguém a recebe e a interpreta. Se ambas seguirem as mesmas regras gramaticais e tiverem o mesmo léxico, a mensagem chega sem mudanças, mas, caso haja mudanças em algum dos elementos de alguma dessas línguas, a tradução pode ser comprometida.

A teoria da semântica enfoca o significado cognitivo e deixa as complexidades da intenção e insinuação para outras disciplinas. Lyons (1987) diz, que a semântica trabalha com problemas de atos ilocucionários, fenômenos paralinguísticos e níveis de interpretações múltiplos.

Sendo assim, no mundo de hoje, a tradução tem uma missão, que muitas vezes é considerada não produtiva, por estabelecer uma comunicação média e censurada, mas representa, na verdade, um meio de trocar idéias entre um indivíduo e outro, é como se fosse um tipo de estação de rádio subterrânea da qual a humanidade se utiliza para mandar notícias para o mundo, sem esperança de ser ouvida, porque a interferência dos sinais é muito forte.

Catford (apud RODRIGUES, 2000, p37)[i] argumenta que a

(...) teoria da tradução diz respeito a certo tipo de relação entre línguas', mas, enquanto as relações entre línguas bidirecionais, ainda que nem sempre simétricas, 'a tradução, como um processo, é sempre unidirecional', sempre realizada de uma línguafonte para uma língua alvo.

Através dessa reflexão, percebe-se que a tradução, apesar do longo percurso que tem percorrido, através de sua história e das teorias que procuram explicá-la, independentemente de ser usada por intérpretes, tradutores ou professores nas aulas de língua estrangeira, não surgiu recentemente no contexto do ensino de línguas e continua sendo discutida por estudiosos e profissionais da área de línguas.

Vários pesquisadores do assunto divergem em suas opiniões e teorias sobre a tradução. No entanto a maioria concorda com a função que ela desempenha e como ela ocorre e, além disso, aponta e acrescenta outros fatores diferenciados, que também devem ser levados em consideração, pois formam um conjunto que pode influenciar a tradução.

Portanto, conclui-se que a tradução, apesar de ser vista de maneira diferenciada pela maior parte dos estudiosos, ocorre até mesmo quando não imaginamos que a estamos usando. Dessa forma, ela é considerada por alguns autores como uma estratégia que facilita a aprendizagem da língua, enquanto outros acreditam que ela em nada contribui para a sua aquisição. Alguns autores destacam que, até mesmo o fato de a criança pedir uma explicação sobre um determinado termo, significa que está fazendo uso da tradução e que a mesma ocorre, na maioria das vezes, involuntariamente, porque não se decide naquele exato momento que se vai traduzir determinado termo ou expressão, mas ela ocorre sem que percebamos, mesmo que mentalmente, o que não deixa de ser uma forma de tradução. 
Então, é de suma importância que novos estudos continuem sendo feitos com relação ao que vem a ser o uso da tradução nas aulas de língua estrangeira realmente, e o que pode ser definido como tradução para que o ensino/aprendizagem de línguas seja melhorado.

Notas:

1 "This principle naturally leads us to associate the language to be learned with what the learner already knows and to use the language for the exploration and extension of this knowledge. To use language, in short, in the way language is, normally used. (...) It provides for the presentation of the foreign language as a relevant and significant communicative activity comparable to the learner's own language. It allows for the devising of exercises which involve the solving of communicative problems, problems which require reference to knowledge other than that which is simply linguistic, which make demands on the linguistic skills only to the extent that they are an intrinsic feature of communicative abilities."

2 "Not every word in one language has an exact equivalent in another. Thus, not all concepts that are expressed through the words of one language are exactly the same as the ones that are expressed through the words of another."

3 "From all this it becomes clear that new concepts are created during the process of learning a foreign language to give meaning to new signs".

\section{REFERÊNCIAS BIBLIOGRÁFICAS}

CAMPOS, Geir. O que é Tradução. São Paulo: Brasiliense, 1986 (Coleção Primeiros Passos).

DRYDEN, John. On Translation. In: Shulte, Rainer; Biguenet, John. (editores) Theories of Translation: an anthology of essays from Dryden to Derrida. Chicago e London : The University of Chicago Press, 1992, p. 17-31.

FRIEDDRICH, Hugo. On the Art of Translation. In: Shulte, Rainer; Biguenet, John. (editores) Theories of Translation: an anthology of essays from Dryden to Derrida. Chicago e London : The University of Chicago Press, 1992, p. 11-16.

FROTA, Maria Paula. Por Uma Redefinição de Subjetividade nos Estudos da Tradução . In: Martins, Márcia A. P. (org) Tradução e Multidisciplinaridade. Rio de Janeiro: Lucerna, 1999, p.52-70.

HUMBOLT, Wilhelm von. From Introduction to His Translation of Agamemnon. In: Shulte, Rainer; Biguenet, John. (editores) Theories of Translation: an anthology of essays from Dryden to 
Derrida. Chicago e London : The University of Chicago Press, 1992, p.55-59.

JAKOBSON, Roman. On Linguistic Aspects of Tranlation. In: Shulte, Rainer; Biguenet, John. (editores) Theories of Translation: an anthology of essays from Dryden to Derrida. Chicago e London : The University of Chicago Press, 1992, p.144-151.

LADMIRAL, Jean-René. A tradução os seus problemas. Lisboa: Edições 70, 1972.

LADMIRAL, Jean-René. TRADUCÃO - Teoremas para a tradução. Lisboa: Publicações Europa-América, 1979.

LYONS, John. Linguagem e Lingüística uma introdução. Rio de Janeiro: Guanabar Koogan S. A., 1987. .

MARTINS, Marcia A. P. Tradução e Multidisciplinaridade. Rio de Janeiro:Lucerna, 1999.

PAZ, Octavio. Tranlation: Literature and Letters. In: Shulte, Rainer; Biguenet, John. (editores) Theories of Translation: an anthology of essays from Dryden to Derrida. Chicago e London : The University of Chicago Press, 1992, p.152-162.

RODRIGUES, Cristina Carneiro. Tradução e diferença. São Paulo: Editora Unesp, 2000.

SCHÄFFER, Ana Maria de Moura. Reflexões Sobre o Papel da tradução (Mental) no Desenvolvimento da Leitura em Língua Estrangeira. Campinas , 2000. 172 f. Dissertação (Mestrado em Linguística Aplicada ) - Instituto de Estudos da Linguagem, Universidade Estadual de Campinas.

SCHOG, Henry. Semantic Theory and Translation Theory. In: Shulte, Rainer; Biguenet, John. (editores) Theories of Translation: an anthology of essays from Dryden to Derrida. Chicago e London : The University of Chicago Press, 1992, p.193-203.

SCHOPENHAUER, Arthur. On Language and Words. In: Shulte, Rainer; Biguenet, John. (editores) Theories of Translation: an anthology of essays from Dryden to Derrida. Chicago e London : The University of Chicago Press, 1992, p.32-35.

SCHULTE, Rainer; BIGUENET, John. Theories of Translation: An Anthology of Essays from Dryden to Derrida. Chicago and London : The University of Chicago Press, 1992.

SMITH, Michael Sharwood. Second Language Learning: Theoretical Foundations. England : Longman, 1997.

WIDDOWSON, H.G. Teaching Language as Communication. Hong Kong: Oxford University Press, 2000.

WYLER, Lia. Uma Perspectiva Multidiciplinar da Tradução no Brasil. In: Martins, Márcia A. P. (org) Tradução e Multidisciplinaridade. Rio de Janeiro: Lucerna, 1999, p. 97-104.

[i] CATFORD, J.C. Uma Teoria Linguística da Tradução: um ensaio em linguística aplicada. Centro de Especialização de Tradutores de Inglês do Instituto da Pontifícia Universidade Católica de Campinas. São Paulo: Cultrix, 1980. 
